Fifth International Conference on Sustainable Construction Materials and

Technologies. http://www.claisse.info/Proceedings.htm

\title{
IMPROVING THE SULFATE ATTACK RESISTANCE OF PORTLAND-LIMESTONE CEMENT THROUGH SULFATE OPTIMIZATION: A CALORIMETRY-BASED APPROACH
}

\author{
Md Manjur A Elahi ${ }^{1}$ and Christopher R. Shearer*1 \\ ${ }^{1}$ Department of Civil and Environmental Engineering, 501 E, Saint Joseph St., Rapid \\ City, SD, USA 57701, chris.shearer@sdsmt.edu, South Dakota School of Mines and \\ Technology \\ *Corresponding Author
}

\begin{abstract}
For portland-limestone cements (PLCs), sulfate optimization is critical for improving their hydration performance. This study investigated the changes in the sulfate attack performance of an undersulfated interground PLC (14.6\% limestone) through the addition of gypsum. Isothermal calorimetry was used to measure the early-age hydration kinetics to optimize the $\mathrm{SO}_{3}$ content of the PLC. Sulfate expansion and strength loss of the undersulfated and optimized PLC was measured in both sodium sulfate and magnesium sulfate solutions. Sulfate optimization of the PLC reduced its expansion to a greater extent in sodium sulfate. Strength loss was also marginally improved at later ages to a greater extent in magnesium sulfate. The improved sulfate attack performance can be attributed in part to the formation of carboaluminate hydrates instead of monosulfate in the optimized PLC. This research highlights the importance of sulfate optimization in achieving PLCs with greater sulfate attack resistance.
\end{abstract}

Keywords: sulfate attack, limestone, hydration, gypsum, expansion, strength loss

\section{INTRODUCTION}

During the last few decades, portland-limestone cement (PLC) has been widely used to reduce the use of raw materials, save fuel energy, and curtail $\mathrm{CO}_{2}$ emissions. In the US, ASTM C595M-17 permits up to $15 \%$ limestone replacement of cement by mass. One important concern with the use of PLCs is the potential development of sulfate attack 
due to the presence of the limestone. PLCs can provide an additional carbonate source, which can promote the formation of a unique type of sulfate attack called thaumasite especially at low temperatures below $15^{\circ} \mathrm{C}$ (Bensted, 2003). Thaumasite mainly occurs after conventional sulfate attack has progressed through the formation of ettringite and/or gypsum (Barcelo et al., 2014). The type of cations associated with $\mathrm{SO}_{4}^{2-}$ (Hartshorn, Sharp, \& Swamy, 1999), the percentage of limestone filler (Hartshorn, Swamy, \& Sharp, 2001), and $\mathrm{C}_{3} \mathrm{~A}$ content (Tosun-Felekoğlu, 2012) are important factors that control the sulfate attack potential of PLCs.

The sulfate content of cement (provided by gypsum) has been shown to influence the sulfate attack performance of ordinary portland cement, however, research has not been conducted on the influence of PLC sulfate content on sulfate attack (Aguayo, 2016). During the hydration of $\mathrm{C}_{3} \mathrm{~A}$, ettringite is formed through the reaction between aluminate and gypsum. When the gypsum depletes, $\mathrm{C}_{3} \mathrm{~A}$ itself reacts with the ettringite to form monosulfate, which can result in an expansive reaction in the presence of external sulfate sources through conversion back to ettringite at later ages. Therefore, obtaining an optimal sulfate content could alter the sulfate attack performance of a cement. In this study, the sulfate resistance of mortar and pastes made from interground PLC with a calcitic limestone content of $14.6 \%$ and two sulfate contents were investigated in sodium and magnesium sulfate solutions. During the initial testing of the PLC, the mortar bar expansion results at 91 days were high and the control cement was confirmed to be undersulfated. Gypsum $\left(\mathrm{as} \mathrm{SO}_{3}\right)$ was added to provide enough sulfate for complete $\mathrm{C}_{3} \mathrm{~A}$ hydration. The expansion of mortar samples and strength loss of paste samples were measured for the undersulfated and sulfate-optimized PLC. The research highlights the importance of sulfate optimization on the sulfate attack performance of PLCs.

\section{EXPERIMENTAL PROGRAM}

\section{Materials}

In this study, the sulfate resistance of PLCs in mortars and pastes placed in sodium sulfate and magnesium sulfate solutions were measured using expansion testing and strength, visual rating, and mass loss, respectively. The performance of Type IL cement with two sulfate contents was compared to that of Type I/II cement. The Type I/II and Type IL cements contain $4.4 \%$ and $14.6 \%$ calcitic limestone (by mass), respectively, interground with the clinker during the manufacturing process. Class $\mathrm{F}$ fly ash was also added to select mixes. Calcium sulfate dihydrate $\left(\mathrm{CaSO}_{4} \cdot 2 \mathrm{H}_{2} \mathrm{O}\right)$ was added to the Type IL cement to optimize its sulfate content, and its sulfate content was quantified as sulfur trioxide $\left(\mathrm{SO}_{3}\right)$ to match the cement. Standard graded sand (ASTM, 2013) was used to make mortar specimens. Quantitative X-ray diffraction (XRD) was performed to determine the clinker composition presented in Table 1. The chemical composition and physical characteristics of cement and filler materials are presented in Table 1.

\section{Mixture Design}


The mixture designs are denoted using the generic placeholders "X-Y-\#\#-F-S", where the designator " $\mathrm{X}$ " represents mortar $(\mathrm{M})$ or paste $(\mathrm{P})$, " $\mathrm{Y}$ " designates Type I/II or Type $1 \mathrm{~L}$ cement, "\#\#" represents the percentage of calcitic limestone in the cement, "F" indicates the use of $20 \%$ fly ash and "S" represents an added $1 \% \mathrm{SO}_{3}$. Refer to the next section for further description on the determination of the added gypsum content. Additionally, $\mathrm{Na}$ and $\mathrm{Mg}$ represent submersion of the specimens in either sodium or magnesium sulfate solutions. Following ASTM C1012 (ASTM, 2018), each mortar bar mixture was proportioned as one-part cement and 2.75 parts standard graded sand, and a water-to-cementitious materials ratio of 0.485 . The details of the mixture designs are presented in Table 2.

Table 1: Chemical composition and physical data for the cements and fly ash

\begin{tabular}{|c|c|c|c|}
\hline Chemical composition (wt. \%) & Type I/II & Type IL & Class F fly ash \\
\hline $\mathrm{SiO}_{2}, \%$ & 19.8 & 17.5 & 52.2 \\
\hline $\mathrm{Al}_{2} \mathrm{O}_{3}, \%$ & 4.7 & 4.3 & 15.9 \\
\hline $\mathrm{Fe}_{2} \mathrm{O}_{3}, \%$ & 3.1 & 3.0 & 5.7 \\
\hline $\mathrm{CaO}, \%$ & 64.8 & 63.6 & 13.0 \\
\hline $\mathrm{MgO}, \%$ & 1.1 & 1.1 & 4.4 \\
\hline $\mathrm{SO}_{3}, \%$ & 3.1 & 3.0 & 0.6 \\
\hline $\mathrm{Na}_{2} \mathrm{O}, \%$ & 0.12 & 0.10 & 2.5 \\
\hline $\mathrm{K}_{2} \mathrm{O}, \%$ & 0.64 & 0.48 & 2.4 \\
\hline $\mathrm{CO}_{2}, \%$ & 1.8 & 6.1 & - \\
\hline LOI, \% & 2.7 & 7.5 & 0.1 \\
\hline \multicolumn{4}{|l|}{ Mineralogical compound (wt. \%) } \\
\hline $\mathrm{C}_{3} \mathrm{~S}, \%$ & 64.2 & 57 & - \\
\hline $\mathrm{C}_{2} \mathrm{~S}, \%$ & 10.9 & 6 & - \\
\hline $\mathrm{C}_{3} \mathrm{~A}, \%$ & 4.3 & 6 & - \\
\hline $\mathrm{C}_{4} \mathrm{AF}, \%$ & 12.1 & 9 & - \\
\hline Equivalent alkalis, \% & 0.54 & 0.42 & 1.5 \\
\hline \multicolumn{4}{|l|}{ Physical characteristics } \\
\hline Blaine fineness $\left(\mathrm{m}^{2} / \mathrm{kg}\right)$ & 429 & 639 & - \\
\hline Residue $45 \mu \mathrm{m}$ sieve $(\%)$ & 3.9 & 99.1 & 21.0 \\
\hline Specific gravity & 3.13 & 3.08 & 2.53 \\
\hline
\end{tabular}

Table 2: Mixture design of mortar bars and paste cubes exposed to sodium and magnesium sulfate solutions

\begin{tabular}{|l|l|c|c|c|}
\hline \multicolumn{1}{|c|}{ Mortar ID } & Paste ID & $\begin{array}{c}\% \\
\text { added } \\
\mathrm{SO}_{3}\end{array}$ & $\begin{array}{c}\% \text { fly } \\
\text { ash }\end{array}$ & w/cm \\
\hline M-I/II-4.4 & P-I/II-4.4 & - & - & 0.485 \\
\hline M-IL-14.6 & P-IL-14.6 & - & - & 0.485 \\
\hline M-IL-14.6-S & P-IL-14.6-S & 1 & - & 0.485 \\
\hline M-IL-14.6-20 & P-IL-14.6-20 & - & 20 & 0.485 \\
\hline M-IL-14.6-20-S & P-IL-14.6-20-S & 1 & 20 & 0.485 \\
\hline
\end{tabular}




\section{Sulfate Optimization Using Isothermal Calorimetry}

To determine the optimum sulfate content of the Type IL cement, the influence of its gypsum content on early-age hydration was evaluated. Five different pastes samples were prepared with an added $\mathrm{SO}_{3}$ content of $0.5 \%, 0.7 \%, 1.0 \%, 1.5 \%$, and $2.0 \%$. The heat of hydration was measured using an I-Cal 4000 HPC isothermal calorimeter. Two $100 \mathrm{~g}$ paste samples were prepared in $150 \mathrm{~mL}$ polymer cups for each mix with a w/cm of 0.485 and placed in the calorimeter chamber for 24 hours at $23^{\circ} \mathrm{C}$.

\section{Mortar Bar Expansion Measurement}

The procedure outlined in ASTM C1012 (ASTM, 2018) was followed to investigate the expansion of mortar specimens exposed to external sulfate. Measuring expansion due to ettringite formation is satisfactory to evaluate the sulfate resistance of PLCs (Barcelo et al., 2014). The mortar mixtures were prepared according to ASTM C305 and ASTM C109. Each mix consisted of $9-2$ in $\times 2$ in $\times 2$ in $(50 \mathrm{~mm} \times 50 \mathrm{~mm} \times 50$ $\mathrm{mm}$ ) mortar cubes and $6-1$ in $\times 1$ in $\times 11.25$ in $(25 \mathrm{~mm} \times 25 \mathrm{~mm} \times 285 \mathrm{~mm})$ mortar bars. Immediately after placement, the molds were covered by a plastic plate and placed over a riser in a closed container filled to $14 \mathrm{~mm}$ below the bottom of the molds with preheated water and stored in an oven at $35^{\circ} \mathrm{C}$ for 24 hours. After 24 hours of initial curing, all bars and cubes, except two cubes, were demolded and submerged in saturated $\mathrm{Ca}(\mathrm{OH})_{2}$ at $23^{\circ} \mathrm{C}$. The 24-hour compressive strength of the two cubes was tested, and subsequently, the compressive strength measurements were monitored daily until the average strength of mortar cubes reached $20 \mathrm{MPa}$ (2850 psi). Once the mortar cubes in a batch gained $20 \mathrm{MPa}(2850 \mathrm{psi})$, their initial length was measured with a digital length comparator according to ASTM C490 (ASTM, 2017). Next, 6 mortars bars were submerged in sodium or magnesium sulfate solution with a $\mathrm{SO}_{4}^{2-}$ concentration of $33800 \mathrm{mg} / \mathrm{L}$ and stored at $23^{\circ} \mathrm{C}$. Afterward, the length of the mortar bars was measured at 1, 2, 3, 4, 8, 13, and 15 weeks and every month until 1 year. The sulfate solution was refreshed after 4,8 , and 13 weeks, and after 6 and 9 months.

\section{Strength Measurement, XRD, and Visual Rating of Pastes}

In this study, a modification of the accelerated test method developed by Kurtis et al. has been followed to evaluate the compressive strength reduction of paste specimens as an indicator of thaumasite sulfate attack (Kurtis, Shomglin, Monteiro, Harvey, \& Roesler, 2001). In this experiment, the compressive strength changes of 0.5 in $\times 0.5$ in $\times 0.5$ in $(12.7 \mathrm{~mm} \times 12.7 \mathrm{~mm} \times 12.7 \mathrm{~mm})$ paste cubes were tested. The standard mixing procedure (ASTM C305) for paste was followed using a w/cm $=0.485$ for all mixtures (see Table 2). After molding, the specimens were covered to avoid shrinkage and kept at $23^{\circ} \mathrm{C}$ for 24 hours. After demolding, the paste cubes were submerged in water and kept in an oven at $50^{\circ} \mathrm{C}$ for 6 more days to accelerate maturity. Afterward, the 7-day compressive strength of 12 cubes for each mixture was determined. The loading rate for the compressive strength test was $45 \mathrm{~N} / \mathrm{sec}$. Then all specimens were placed in a large bin of sodium and magnesium sulfate solution $\left(\mathrm{SO}_{4}^{2-}\right.$ concentration of 33800 $\mathrm{mg} / \mathrm{L}$ ) placed at $5 \pm 1^{\circ} \mathrm{C}$ to promote the formation of thaumasite. Compressive strength was measured at $14,28,56,91$, and 120 days after the immersion of samples in sulfate environments. The visual inspection was performed at 180 days to identify surface 
deterioration. A microstructural investigation using XRD was performed on all paste samples to identify the sulfate attack products after 180 days of exposure.

\section{RESULTS AND DISCUSSION}

\section{Sulfate Optimization of Type IL Cement}

Sulfate optimization of the Type IL cement was determined using early-age heat signatures as measured by isothermal calorimetry. The power and energy curves normalized per gram of cementitious materials are presented in

Figure 1. In

Figure 1-b, the first peak is correlated to the hydration of $\mathrm{C}_{3} \mathrm{~S}$ and for some samples is followed by a second peak associated with the hydration of $\mathrm{C}_{3} \mathrm{~A}$. The unaltered Type IL PLC exhibits only one major peak indicating it is undersulfated (Bullard et al., 2011). The addition of gypsum to the Type IL cement resulted in a visible secondary peak on the curve associated with the depletion of sulfates. This is more pronounced in PLC systems (Barrett, Sun, \& Weiss, 2013).
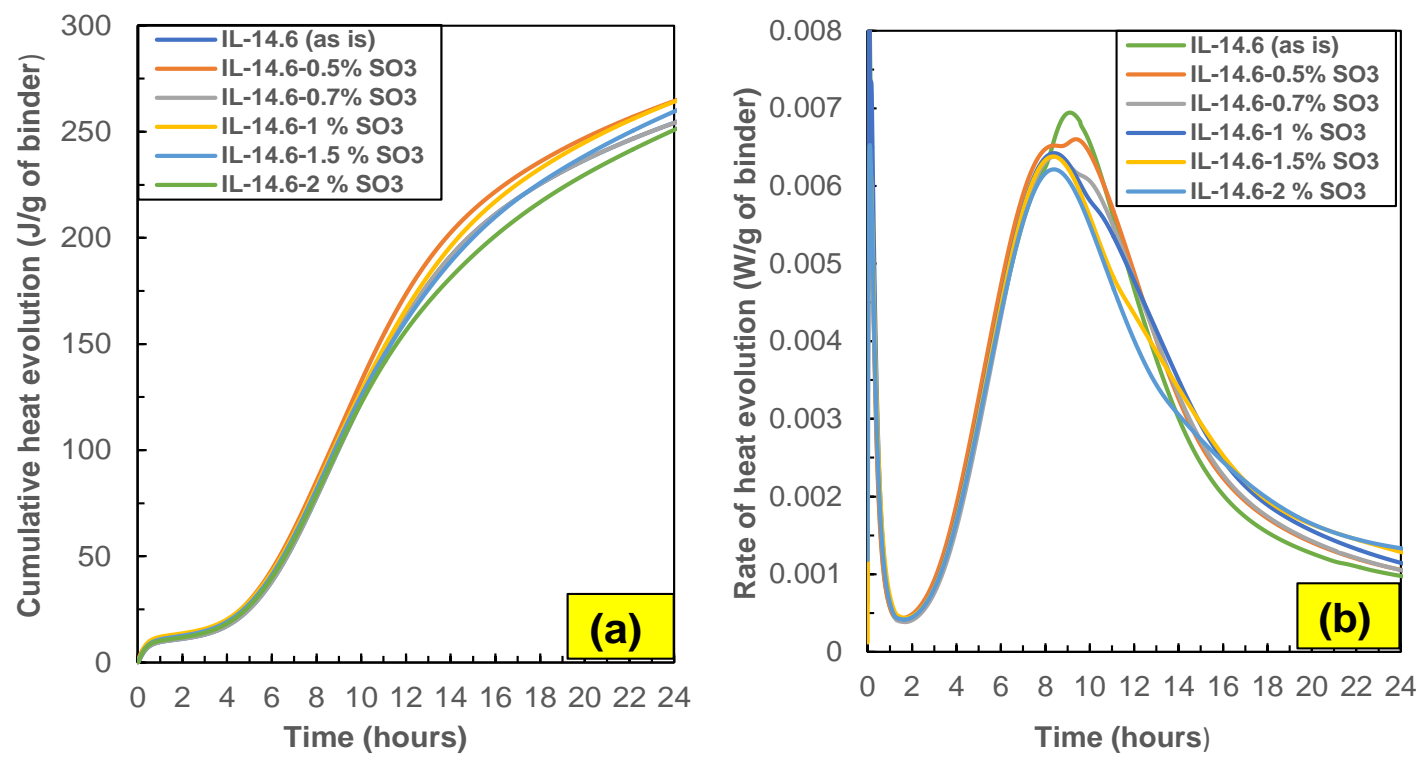

Figure 1: Calorimetry curve of PLC with different dosage of gypsum, (a) cumulative heat evolution and (b) rate of heat evolution per gram of binder

An additional $1 \% \mathrm{SO}_{3}$ was found to be the optimum sulfate content. This was determined by plotting the cumulative heat released after 24 hours for a range of added $\mathrm{SO}_{3}$ contents $(0.5 \%-2 \%)$ as shown in Figure 1-a. The maximum cumulative heat liberated after 24 hours relative to all other mixes for the Type IL cement was selected as its optimized $\mathrm{SO}_{3}$ content (i.e., $1 \%$ added $\mathrm{SO}_{3}$ ). The cumulative heat evolution of IL-14.6-S is 5\% higher than the control PLC (IL-14.6) cement after 24 hours as shown in Figure 2-a. The power and energy curves of the PLC in combination with fly ash and $1 \% \mathrm{SO}_{3}$ presented in Figure 2 reveal that more heat (roughly 9\%) was produced after 
24 hours when fly ash was added to the PLC with optimized sulfate compared to the undersulfated condition. This is likely due to a synergistic nucleation effect caused by the limestone in the presence of fly ash.
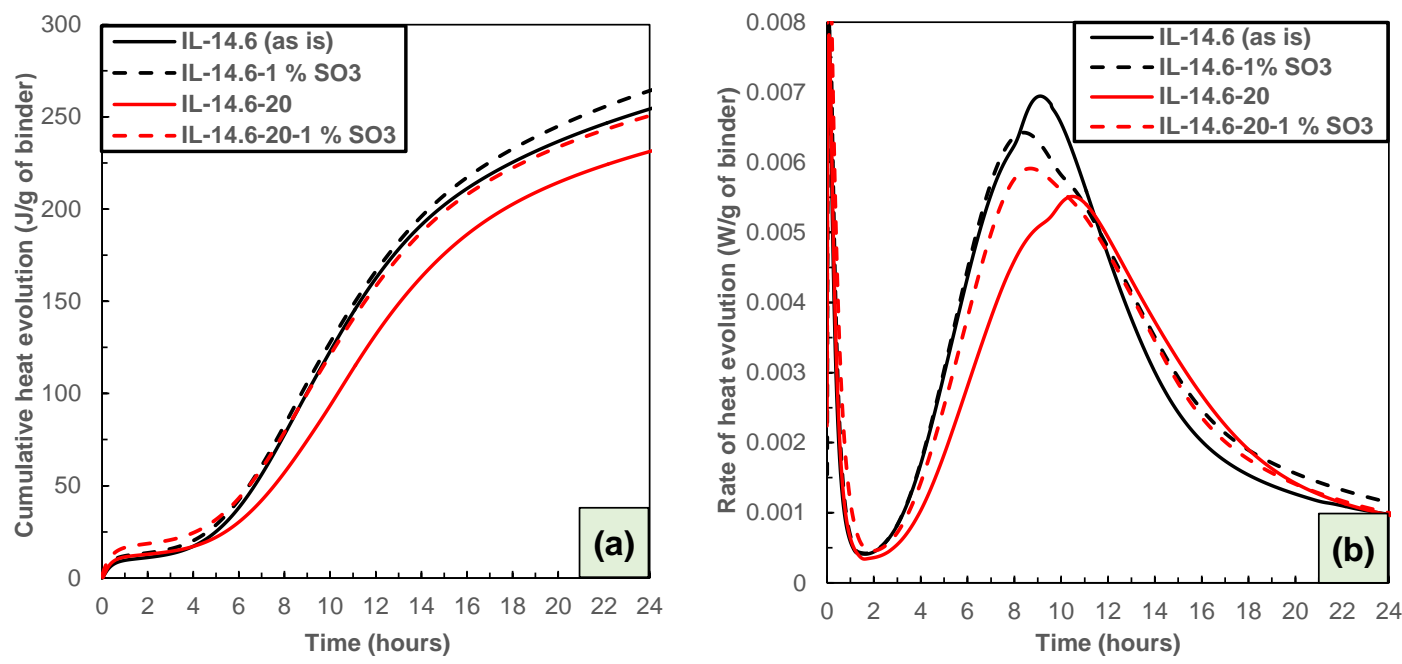

Figure 2: Calorimetry curve of PLC and its fly ash blend with 1\% gypsum, (a) cumulative heat evolution and (b) rate of heat evolution per gram of binder

XRD analysis of pastes made with the undersulfated Type IL cement reveal that calcium sulfoaluminate hydrate (monosulfate) was formed at 1 day and intensified after 7 days as shown in Figure 3. In contrast, hemicarboaluminate and monocarboaluminate were detected instead of monosulfate in the hydrated optimized Type IL cement at both ages. This indicates that the addition of gypsum has influenced the hydration of PLC to form carboaluminate hydrates, which has controlled the conversion of ettringite to monosulfate. This phenomenon has been reported previously and is known as ettringite stabilization (De Weerdt, Kjellsen, Sellevold, \& Justnes, 2011; Lothenbach, Le Saout, Gallucci, \& Scrivener, 2008). 


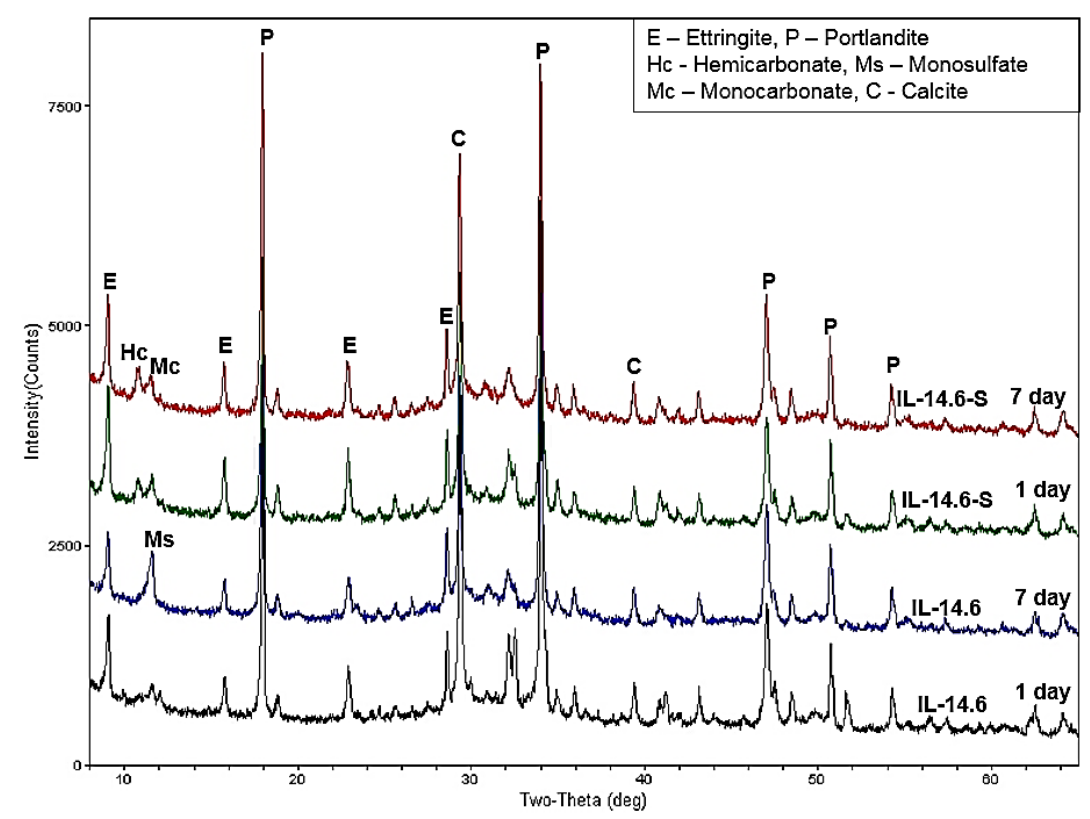

Figure 3: XRD analysis of hydrated paste at 1 and 7 days

\section{Mortar Bar Expansion}

The expansion results of the mortar specimens of different PLC blends submersed in sodium and magnesium sulfate solution are shown in Figure 4. For both solution types, the M-I/II-4.4 cement had a lower expansion compared to the M-IL-14.6 cement. One of the potential reasons for the significantly higher expansion in the M-IL-14.6 could be its higher $\mathrm{C}_{3} \mathrm{~A}(6 \%)$ content and its higher limestone content, which has been shown to negatively influence sulfate performance. Its undersulfated condition also contributed to its higher expansion as will be discussed later.

Expansion was quicker for all samples in sodium sulfate compared to magnesium sulfate. This is probably due to the formation of a brucite layer at the exposed surface of the specimens in the magnesium sulfate, which restricts the magnesium ion penetration into the interior matrix of mortar samples reported elsewhere (Bonen \& Cohen, 1992; Santhanam, 2001). The addition of fly ash to the PLC slightly reduced expansion in Mg but it increased expansion in Na. Generally, Class F fly ash takes time (around 3 months) to start its pozzolanic reaction, which could be a reason for its poor performance here. PLCs with fly ash with a $\mathrm{CaO}<8 \%$ perform better in sulfate environments compared to fly ashes with higher calcium contents (Hossack \& Thomas, 2015 ) in part due to the higher $\mathrm{C}_{3} \mathrm{~A}$ contents of high $\mathrm{CaO}$ ashes. In this study, the fly ash used contains $13 \% \mathrm{CaO}$ which could be another potential reason for not significantly improving the sulfate resistance of this PLC. Regardless, both the M-IL14.6 and M-IL-14.6-20 mixtures were disintegrated after 6 months and 7 months in sodium sulfate, respectively shown in Figure $5(\mathrm{a}, \mathrm{c})$. After one year in magnesium sulfate, both these samples reached close to $3 \%$ expansion. While the samples were still intact, they were well above the limit specified in ASTM C595. In fact, all the PLC 
mixtures in both solutions exceeded the ASTM C595 6-month expansion limit (0.05\%) for high sulfate resistance on or before 90 days.

The addition of sulfate to optimize the PLC influenced its sulfate attack performance. Images of the mortar specimens placed in sodium and magnesium sulfates are shown in Figure 5 (b, d, f, h). After 6 months exposure in both $\mathrm{Na}$ and $\mathrm{Mg}$, the sulfate optimization significantly improved the visual appearance of all specimens. In $\mathrm{Na}$, the expansion patterns of all mixes were similar up to 120 days after which the optimized mixes had a reduced expansion. Still, the sulfate-optimized specimens disintegrated at a slightly later age (240 days) compared to the undersulfated specimens. In contrast, a comparatively higher expansion reduction was observed for the sulfate-optimized PLC blends when placed in $\mathrm{Mg}$. With the added $\mathrm{SO}_{3}$, the expansion reduction was $59 \%$ and 54\% for M-IL-14.6-S and M-IL-14.6-20-S mixtures, respectively, compared to their control mixtures at 240 days. Therefore, sulfate-optimization only marginally improved the sulfate attack performance in sodium sulfate, but significantly improved it in magnesium sulfate.

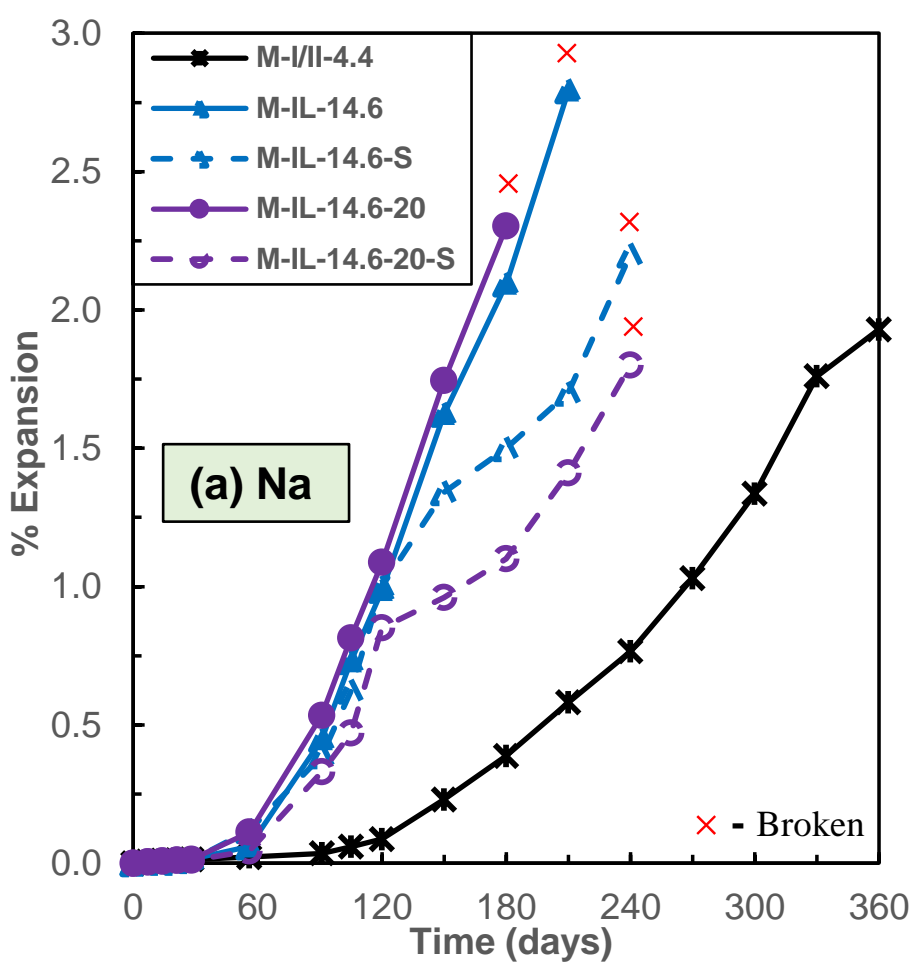




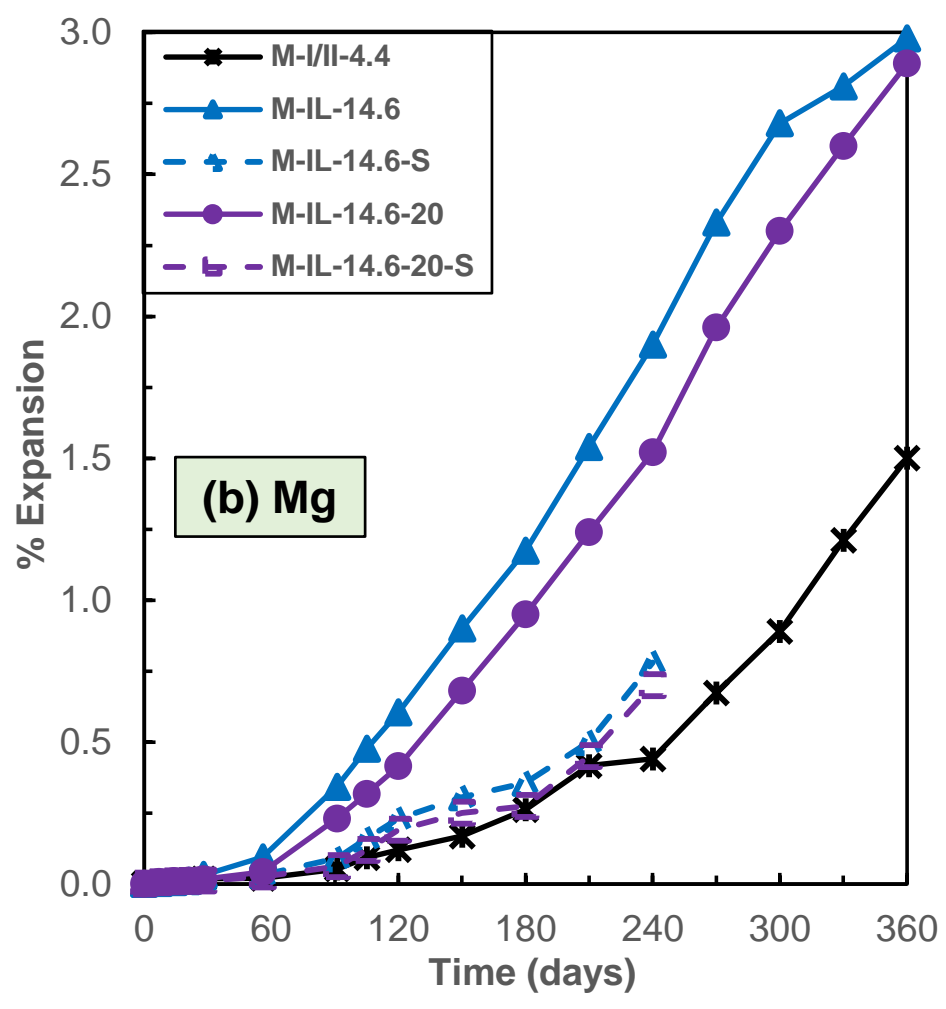

Figure 4: Expansion of PLC mortars placed in $5 \%$ at $23^{\circ} \mathrm{C}$ in (a) sodium sulfate solution and (b) magnesium sulfate solution
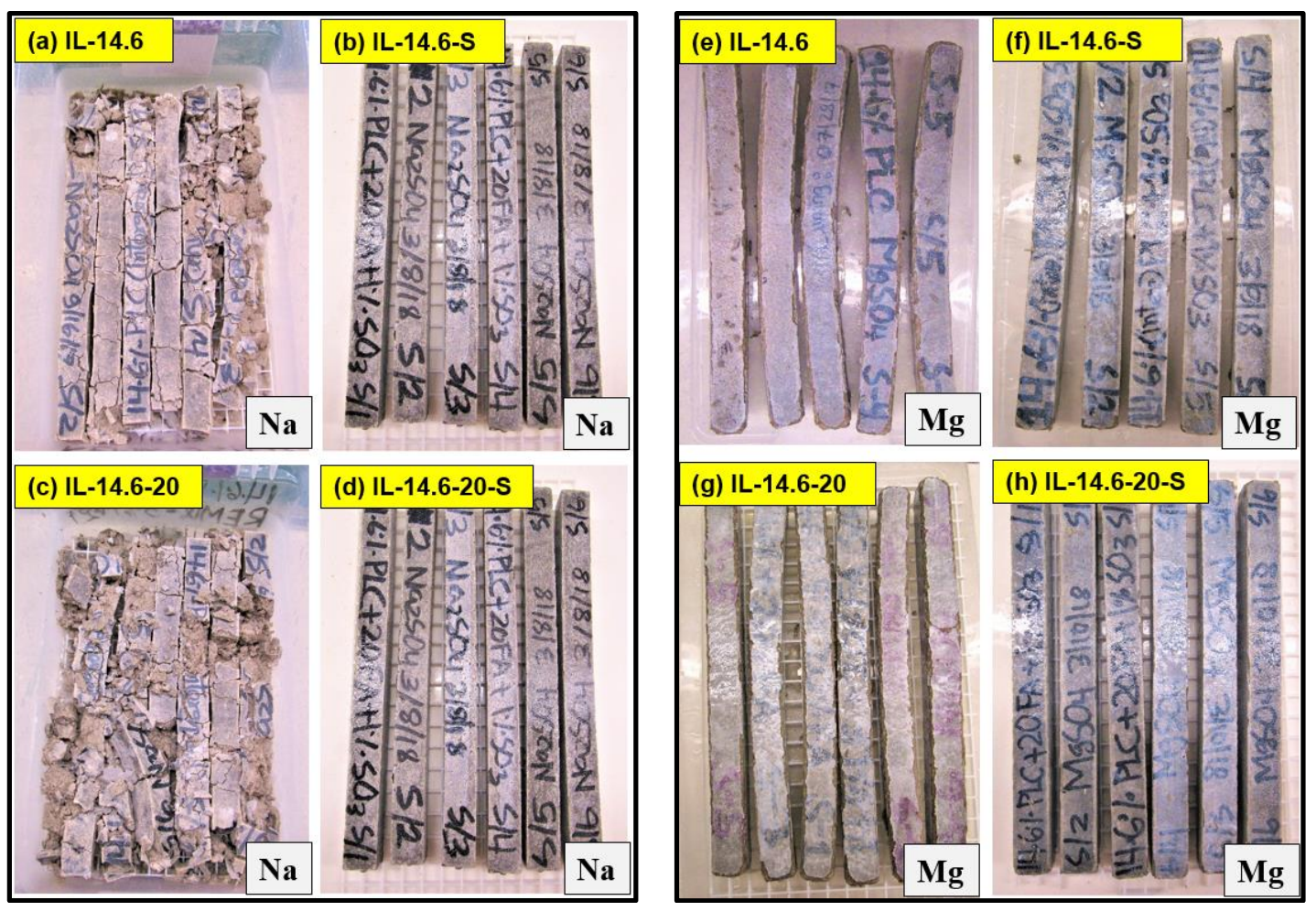
Figure 5: Images of mortar samples exposed to sodium (a-d) and magnesium (e-h) sulfate solution exposures at 6 months

\section{Compressive Strength of Paste Specimens}

The undersulfated and sulfate-optimized IL-14.6 and IL-14.6-20 cement mixtures were also evaluated for compressive strength change in a sulfate environment over an exposure period of 180 days. The percent reduction in compressive strength (relative to an initial 7-day strength) at different ages in $\mathrm{Na}$ and $\mathrm{Mg}$ solution at $5^{\circ} \mathrm{C}$ is presented in Figure 6 and Figure 7, respectively. Over the 180-day exposure period the samples underwent both strength increases and decreases. The strength increases can be potentially explained by the continued hydration of unhydrated cement particles (mostly $\mathrm{C}_{3} \mathrm{~S}$ and $\mathrm{C}_{2} \mathrm{~S}$ ) which produced more hydration products, primarily $\mathrm{C}-\mathrm{S}-\mathrm{H}$, leading to higher compressive. Strength losses are mainly attributed to sulfate attack.

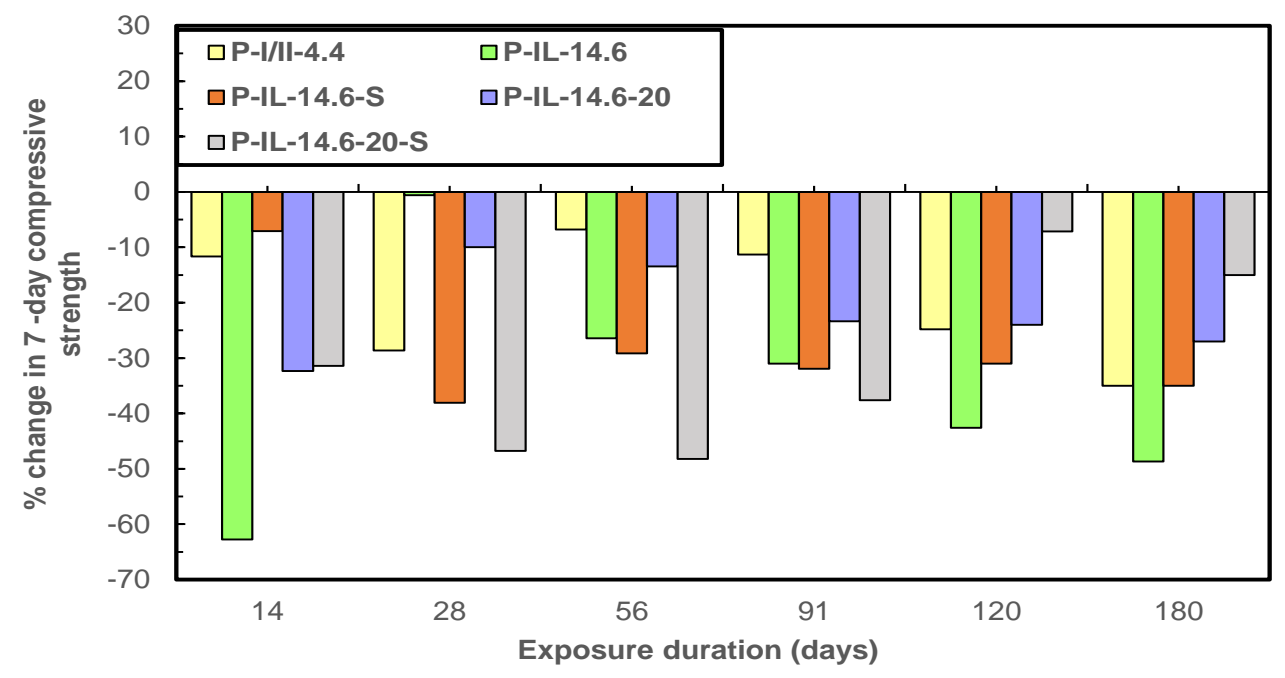

Figure 6: Percent reduction of compressive strength in sodium sulfate at $5^{\circ} \mathrm{C}$ 


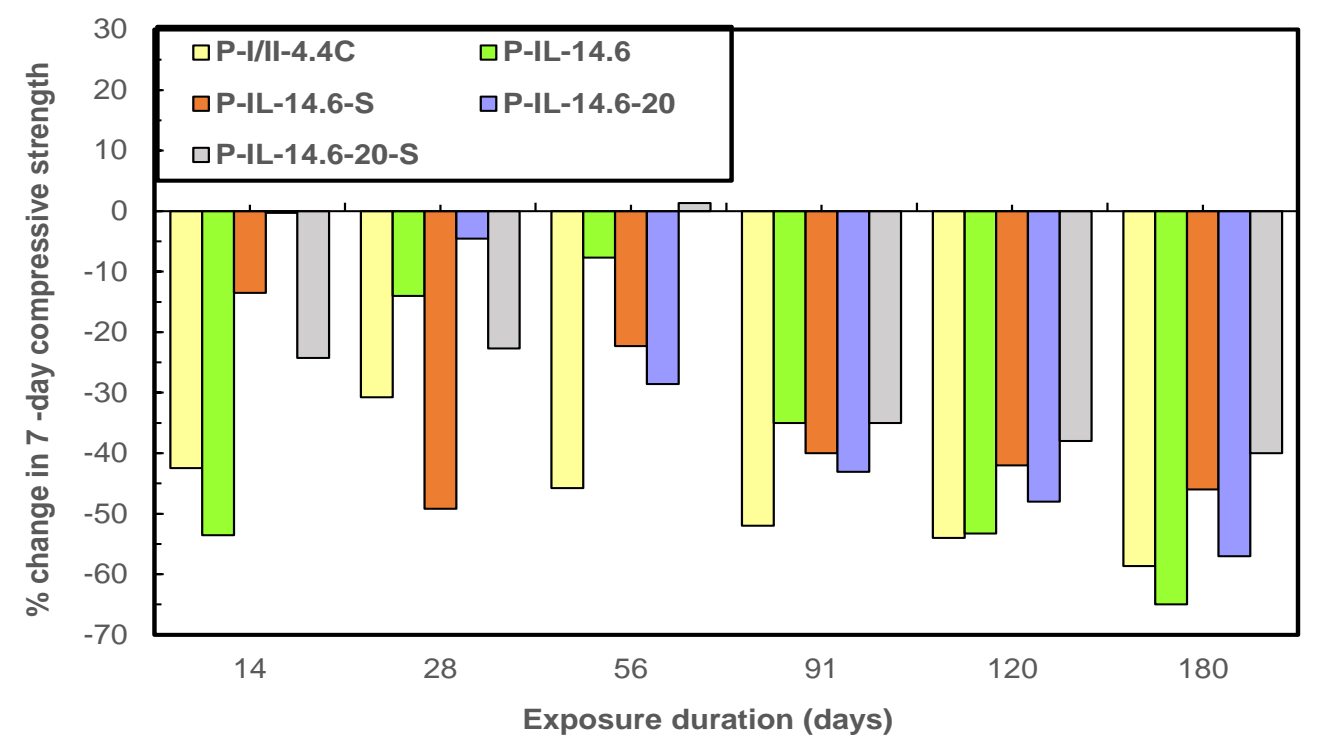

Figure 7: Percent reduction of compressive strength in magnesium sulfate at $5^{\circ} \mathrm{C}$

At later ages, strength loss was greater in the Type IL cement compared to the Type I/II cement, which corresponds to expansion data. The addition of fly ash marginally improved strength loss for the undersulfated PLC. Sulfate optimization of the PLC also marginally improved strength loss in both solutions. The sulfate-optimized fly ash blended PLC mix performed best, especially in sodium sulfate. In this experiment, the elevated curing temperature may have accelerated the pozzolanic reaction, resulting in the enhanced performance of the fly ash mix seen here. Fly ash and limestone also can have a synergistic effect that results in the formation of calcium carboaluminate hydrate which stabilizes ettringite and improves mechanical properties (De Weerdt, Kjellsen, Sellevold, \& Justnes, 2011). This could have contributed to its improved sulfate attack performance, especially with the sulfate balanced.

The sulfate attack products formed for these samples in $\mathrm{Na}$ and $\mathrm{Mg}$ exposures as detected by XRD at $5^{\circ} \mathrm{C}$ at 120 days are shown in Figure 8. The sulfate solution cation type affected the compressive strength and expansion results in a different manner. While the increase in the expansion was higher for specimens exposed to sodium sulfate solution, compressive strength decreased more in magnesium-exposed samples. As evidenced by the XRD results, gypsum formation was only observed in the magnesium sulfate samples, which accounts for their greater strength loss. For all samples, the co-existence of ettringite and thaumasite was observed at $2 \theta=9.12^{\circ}$ in both exposures, regardless of the sulfate optimization. The addition of gypsum to the P-IL-14.6 mixture likely formed carboaluminate hydrates (as shown in Figure 3), which eventually reduced the permeability of the overall system and controlled the ingress of external sulfates (Bonavetti, Rahhal, \& Irassar, 2001; Irassar et al., 2011). As a result, these samples exhibited lower strength loss and lower expansion. At $2 \theta \sim 12^{\circ}$ and $21^{\circ}$, the ettringite and gypsum peak intensities are lower for the optimized sulfate blends, which supports this assertion. 


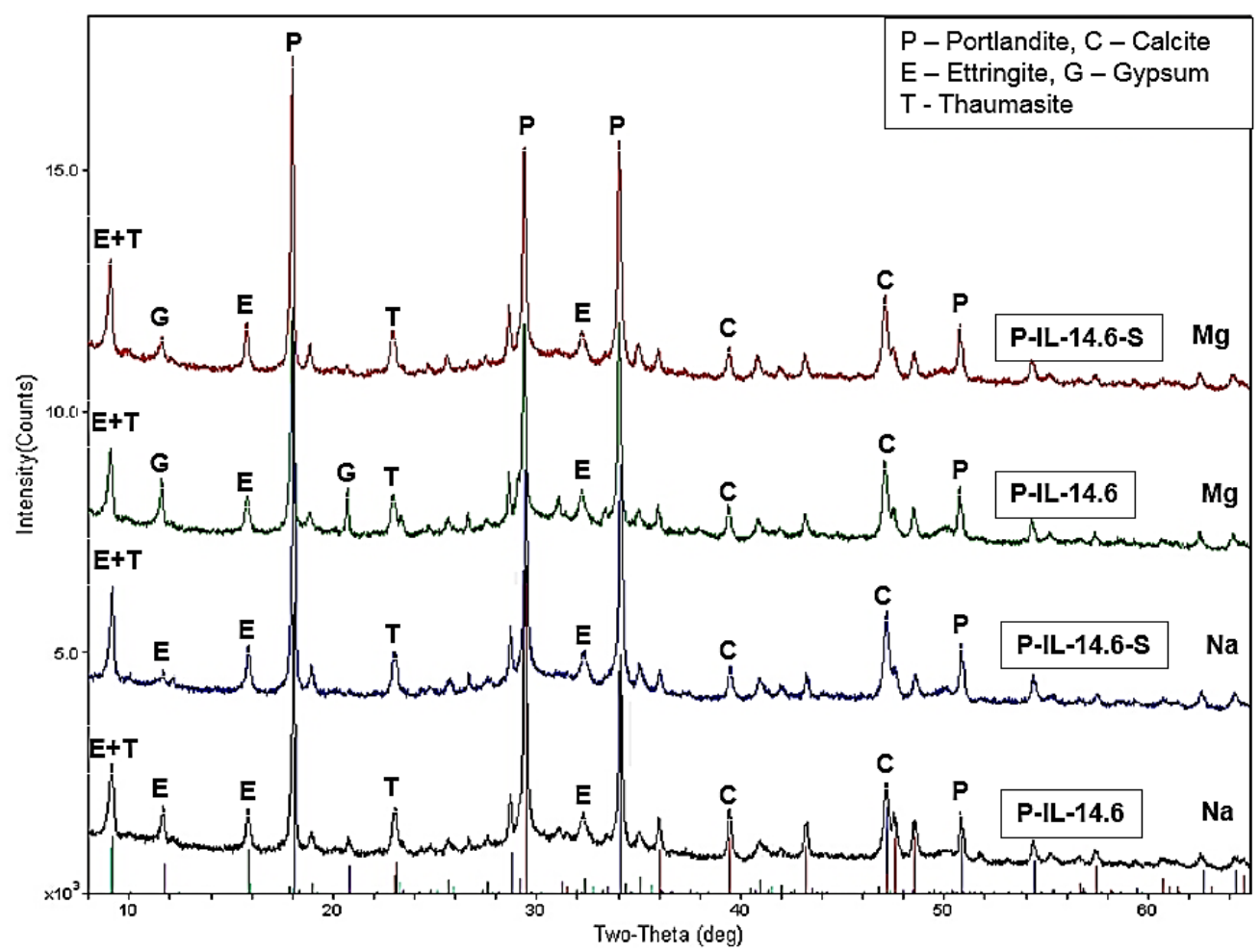

Figure 8: XRD analysis of paste exposed to sodium and magnesium sulfate solution at $5^{\circ} \mathrm{C}$ at 120 days

The visual appearance of paste samples placed in sulfate exposures is shown in Figure 9. The samples placed in Na showed less cracking, spalling, and surface deterioration than those placed in Mg (Figure 9 a-d). For IL-14.6, more surface deterioration with extensive cracking, spalling, and bulging was observed for samples without added $\mathrm{SO}_{3}$ when placed in both solutions (Figure $9 \mathrm{e}, \mathrm{g}$ ). This supports the strength loss results, where sulfate optimization improved (marginally) the sulfate attack performance.
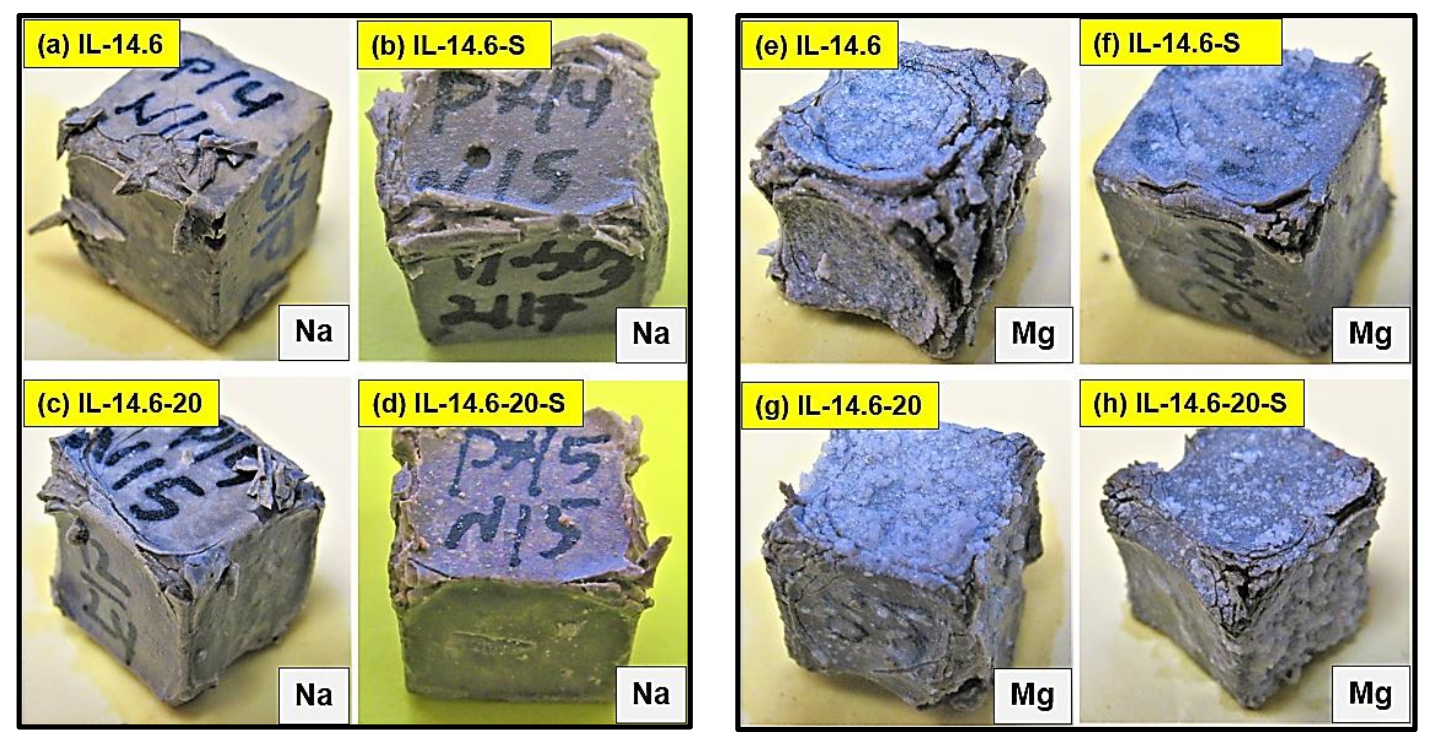
Figure 9: Visual appearance change of paste cubes placed in sodium (a-d) and magnesium (e-f) sulfate solution at $5^{\circ} \mathrm{C}$ at 180 days

\section{CONCLUSION}

The influence of sulfate optimization on the sulfate attack performance of PLCs was studied. The undersulfated PLC exhibited high expansion and strength reduction when exposed to both sodium sulfate and magnesium sulfate solutions. The addition of gypsum to achieve sulfate optimization for the PLC via a calorimetry method increased early-age heat release and led to the formation of carboaluminate hydrates instead of monosulfate. As a result, its sulfate attack expansion was improved, with greater expansion reduction observed in sodium sulfate compared to magnesium sulfate. Strength loss was also marginally improved at later ages for the sulfate optimized PLC, with greater strength reduction observed in magnesium sulfate compared to sodium sulfate. The addition of fly ash resulted in slightly lower expansion and lower strength loss due to its synergistic effect with limestone. Overall, sulfate optimization is crucial in improving the sulfate resistance of PLCs.

\section{REFERENCES}

Aguayo, F. M. (2016). External Sulfate attack of concrete : an accelerated test method, mecanism, and mitigation techniques PhD Dissertation (Vol. The University of Texas at Austin).

ASTM. (2013). Standard specification for standard sand. C778-13.

ASTM. (2017). Standard Practice for Use of Apparatus for the Determination of Length Change of Hardened Cement Paste, Mortar, and Concrete.

ASTM. (2018). Standard Test Method for Length Change of Hydraulic-Cement Mortars Exposed to a Sulfate Solution C1012M-18a: ASTM International

Barcelo, L., Gartner, E., Barbarulo, R., Hossack, A., Ahani, R., Thomas, M., . . . Blair, B. (2014). A modified ASTM C1012 procedure for qualifying blended cements containing limestone and SCMs for use in sulfate-rich environments. Cement and Concrete Research, 63, 75-88.

Barrett, T. J., Sun, H., \& Weiss, W. J. (2013). Performance of portland limestone cements: Cements designed to be more sustainable that include up to $15 \%$ limestone addition.

Bensted, J. (2003). Thaumasite — direct, woodfordite and other possible formation routes. Cement and Concrete Composites, 25(8), 873-877.

Bonavetti, V., Rahhal, V., \& Irassar, E. (2001). Studies on the carboaluminate formation in limestone filler-blended cements. Cement and Concrete Research, 31(6), 853-859.

Bonen, D., \& Cohen, M. D. (1992). Magnesium sulfate attack on portland cement paste-I. Microstructural analysis. Cement and Concrete Research, 22(1), 169180. 
Bullard, J. W., Jennings, H. M., Livingston, R. A., Nonat, A., Scherer, G. W., Schweitzer, J. S., . . Thomas, J. J. (2011). Mechanisms of cement hydration. Cement and Concrete Research, 41(12), 1208-1223.

De Weerdt, K., Kjellsen, K., Sellevold, E., \& Justnes, H. (2011). Synergy between fly ash and limestone powder in ternary cements. Cement and Concrete Composites, 33(1), 30-38.

Hartshorn, S., Sharp, J., \& Swamy, R. (1999). Thaumasite formation in Portlandlimestone cement pastes. Cement and Concrete Research, 29(8), 1331-1340.

Hartshorn, S., Swamy, R., \& Sharp, J. (2001). Engineering properties and structural implications of Portland limestone cement mortar exposed to magnesium sulphate attack. Advances in cement research, 13(1), 31-46.

Hossack, A. M., \& Thomas, M. D. (2015). Evaluation of the effect of tricalcium aluminate content on the severity of sulfate attack in Portland cement and Portland limestone cement mortars. Cement and Concrete Composites, 56, 115-120.

Irassar, E., Violini, D., Rahhal, V., Milanesi, C., Trezza, M., \& Bonavetti, V. (2011). Influence of limestone content, gypsum content and fineness on early age properties of Portland limestone cement produced by inter-grinding. Cement and Concrete Composites, 33(2), 192-200.

Kurtis, K., Shomglin, K., Monteiro, P., Harvey, J., \& Roesler, J. (2001). Accelerated test for measuring sulfate resistance of calcium sulfoaluminate, calcium aluminate, and Portland cements. Journal of materials in civil engineering, 13(3), 216-221.

Lothenbach, B., Le Saout, G., Gallucci, E., \& Scrivener, K. (2008). Influence of limestone on the hydration of Portland cements. Cement and Concrete Research, 38(6), 848-860.

Santhanam, M. (2001). Studies on sulfate attack: mechanisms, test methods, and modeling.

Tosun-Felekoğlu, K. (2012). The effect of C3A content on sulfate durability of Portland limestone cement mortars. Construction and Building Materials, 36, 437-447. 